\title{
Taburculuğa Hazırlanan Preterm İnfantlarda Kritik Olmayan Morfolojik Deformiteler
}

\author{
Non-critical Morphological Deformities in Discharge Preterm Infants
}

Nuriye Tarakçı, Hüseyin Altunhan

Necmettin Erbakan Üniversitesi, Meram Tip Fakültesi, Çocuk Sağ̆lğı ve Hastalıkları ABD, Neonatoloji BD, Konya, Türkiye

Yazı̧ıma Adresi / Correspondence:

Nuriye Tarakçı

Necmettin Erbakan Üniversitesi, Meram Tip Fakültesi, Çocuk Sağlı̆ı ve Hastalıkları ABD, Neonatoloji BD, 42080, Konya, TÜRKIYE

T: +90332 2236060 E-mail: nuriyetarakci@hotmail.com

Geliş Tarihi / Received : 15.11.2018 Kabul Tarihi / Accepted : 02.01.2019

\footnotetext{
Öz

Amaç Bu çalışmada yenidoğan yoğun bakım kliniğinde izlenen preterm infantlarda tedavileri sırasında ortaya çıkan ve taburcu sırasında devam eden kritik olmayan hasarları ve risk faktörlerini değerlendirmek amaçlanmıştır. ( Sakarya Tip Dergisi 2019, 9(1):16-21 )

Gereç ve Necmettin Erbakan Üniversitesi Meram Tip Fakültesi yenidoğan yoğun bakım ünitesinde 2011 ile 2017 yllları arasında tedavi edilen preterm bebeklerin tedaviye bağlı Yöntemler olduğu düșünülen deformiteleri ve risk faktörleri retrospektif olarak kaydedildi.

Bulgular Çalışmada 1040 preterm infant retrospektif olarak değerlendirildi. En sık görülen deformite kafatası șekil bozukluğu idi (\%14.4). Nazal Sürekli Pozitif Havayolu Basıncı (nCPAP)’a bağlı nazal deformasyon (\%13.8) ikinci sıklıkta gözlendi. En sık risk faktörü sürekli sabit pozisyon ve nCPAP uygulaması idi.

Sonuç Preterm infantların yaşam şansları arttıkça deformasyona neden olabilecek enstürmanlarla karşılaşmaları da artmaktadır. Başlangıçta bebeklerinin yaşadığının sevincinde olan ebeveynler bu problemleri sorun etmese de bu infantlar büyüdüğünde onlarda psikolojik sorunlara neden olabileceği unutulmamalı ve bu deformasyon oluşumunu önleyebilmek için gerekli özen gösterilmelidir.

Anahtar prematüre; morfolojik deformite; taburcu bebek

Kelimeler

Abstract

Objective To evaluate the non-critical damages that occurred during the discharge of the patients in preterm infants in the neonatal intensive care unit and their risk factors ( Sakarya Med J 2019, 9(1):16-21)

Materials and We retrospectively evaluated treatment related deformities and risk factors of preterm infants who were treated in the neonatal intensive care unit at Necmettin Erbakan University Meram Methods Medical Faculty between 2011 and 2017.

Results A total of 1040 preterm infants were evaluated retrospectively. The most common deformity was skull deformity (14.4\%). Nasal deformation (13.8\%) due to nasal continuous positive airway pressure (nCPAP) was the second most common. The most common risk factor was continuous fixed position and nCPAP application.

Conclusion As the survival chances of the preterm infants increase, their encounter with the instruments that may cause deformation increases. Although parents who are initially delighted by their babies living do not mind these problems, it should be kept in mind that these infants may cause psychological problems when they grow up, and care should be taken to prevent this deformation.

Keywords premature; morphological deformity; discharge baby
} 


\section{GíRiș}

Son yıllarda dünyada perinatal ve neonatal bakımda artan tecrübe ve teknolojik gelişmelerle birlikte prematüre bebeklerin solunum sıkıntısı sendromu, intraventriküler kanama ve enfeksiyonlar gibi çok kritik komplikasyonları azalmış ve çok küçük preterm bebeklerin yaşam şansları artmıştır. Bu durumun erken ve geç dönemde yaşamı tehdit etmeyen ve yenidoğan yoğun bakım uygulamalarının olumsuz sonuçlarına bağlı bazı morbiditelere neden olduğu görülmüştür. ${ }^{1}$ Ortaya çıkan bu bozuklukların çoğu zamanla düzelirken bazıları ise fonksiyonel ve estetistik bakımdan sorunlara neden olmakta ve hatta rekonstrüktif tedavilere gereksinim göstermektedir. Preterm infantların kritik sorunlarının taburculuk sırasında ve sonrasında değerlendirildiği pek çok çalışma var. Literatürde invaziv ve noninvaziv girişimler sırasında nazal yaralanma, palatal hasar, dermal kalsinozis gibi komplikasyonların tek başına değerlendirildiği çalışmalar da bulunmaktadır. ${ }^{1,2}$ Ancak bildiğimiz kadarıyla preterm bebeklerin kritik olmayan ne tür sorunlarla taburcu edildiği üzerine bir çalışma bulunmamaktadır. Biz bu çalışmamızda yenidoğan yoğun bakım kliniğinde izlenen preterm infantlarda tedavileri sırasında ortaya çıkan hasarlar ve risk faktörlerini retrospektif olarak değerlendirdik.

\section{GEREÇ ve YÖNTEM}

Ocak 2011-Aralık 2017 tarihleri arasında Necmettin Erbakan Üniversitesi Meram Tıp Fakültesi Üçüncü Basamak Yenidoğan Yoğun Bakım Ünitesinde izlenen hastaları kapsayan tanımlayıcı çalışmada hastaların verileri hastane kayıtlarından retrospektif değerlendirildi. Çalışmaya 32 haftadan küçük üçüncü düzey yoğun bakım gerektiren ve yaşayan tüm infantlar alındı. Konjenital anomaliye bağlı dismorfik özellikleri olan, tedavisi devam ederken ölen ve cerrahi gerektiren hastalar çalışmaya dahil edilmedi. Hastaların gebelik haftası, doğum ağırlığı, fizik muayene bulguları kaydedildi. Tüm hastaların hastanede yattığı süre boyunca aldığı tedaviler ( intravenöz kalsiyum infüzyonu, total paranteral nutrisyon), invaziv ve noninvaziv girişimler (torax tüpü, eksternal ventriküler drenaj sistemi
(EVDS), periton diyalizi, endotrakeal tüp uygulaması, nCPAP, orogastrik (OG) veya nazogastrik (NG) feeding) ve uygulama süreleri kaydedildi. Hastaların taburculuğu s1rasında yapılan fizik muayenelerinde gözlenen farklılıklar kaydedildi. Çalışma için Necmettin Erbakan Üniversitesi Meram Tip Fakültesi etik kurulundan onay alındı.

Veri kullanımı ve istatistik analizi SPSS 20 (SPSS Inc., Chicago, IL, ABD) kullanılarak yapıldı. Tanımlayıcı istatistikler kesikli sayısal değişkenler için ortalama \pm standart sapma (SS) biçiminde gösterilirken kategorik ve sıralanabilir değişkenler olgu sayısı ve (\%) şeklinde ifade edildi.

\section{BULGULAR}

Çalışmada 1040 preterm infant retrospektif olarak değerlendirildi. 32 hasta konjenital anomaliye bağlı dismorfik görünüm, 6 hasta taburculuk sırasında ayrıntılı fizik muayene bulgularının olmaması nedeniyle çalışmaya dahil edilmedi. Hastaların ortalama gebelik haftası $29.36 \pm 2.37$, ortalama doğum ağırlığı $1248.16 \pm 389.4$ gr, ortalama hastanede yatış süresi $70 \pm 13$ gün idi. Mekanik ventilatör (MV); 200/1002 (\%19.9), nCPAP; 600/1002 (\%59.9), pnömotoraks nedeni ile torax tüpü; 68/1002 (\%6.8), periton diyalizi; 24/1002 (\%2.4) hastaya uygulandı. Posthemorajik hidrosefali nedeni ile eksternal ventriküler drenaj sistemi veya rezervuar takilan hasta sayısı 16/1002 (\%1.6), solunum problemi nedeni ile trakeostomi açılan hasta sayısı 5/1002 (\%0.5), enteral beslenmeyi başaramadığı için OG sonda ile taburcu edilen hasta sayısı 40/1002 (\%3.99) idi (Tablo 1).

Taburcu sırasında yapılan fizik muayenede saptanan deformiteler ve risk faktörleri Tablo 2'de gösterildi. Hastaların \%14.4 (144/1002)'ünde kafatası şeklinde deformite, \%3 (30/1002)'ünde tek taraflı kulak deformitesi, \%1.3 (13/1002)'ünde üst dudak ve yumuşak damakta oluklanma (endotrakeal tüp ve/veya OG sondaya bağlı) gözlendi. nCPAP ihtiyacı olan hastaların \%13.8 (83/600)'inde nCPAP bağlı nazal septumun ön kısmında deformite tespit edildi. Bunların dışında torax tüpü, periton diyaliz, patent 
duktus arteriosus (PDA) ligasyonu gibi girişimsel işlemlere ait skarlar ve ilaç ekstravazasyonu sonucu oluşan deformiteler tespit edildi.

\section{TARTISSMA}

Bu çalışmada yenidoğan yoğun bakımda tedavi edilen preterm bebeklerin taburcu anında kritik olmayan hasarlanmaları değerlendirildi.

Preterm infantlar intrauterin hayattan ekstrauterin hayata adaptasyon sürecini yenidoğan yoğun bakım ünitesinde geçirmektedirler. Bu sürede preterm infantlar çoğu önlenebilir mekanik problemlerle karşılaşabilmektedir. Doğum sonrası hayatta yerçekimi ve preterm bebeklerin pozisyonu kranial, palatal ve fasiyal kemiklerde deviasyonlara sebep olabilir. Bu da preterm infantın fasiyal görünümünü değiştirebilir. ${ }^{3}$ Bebeğin kraniumunun yumuşak ya da şekil verilebilir olması kraniumun düz bir yüzey üzerine yatırıldığında düzleşmesine yol açar. Özellikle posterior deformasyonel plagiosefalinin sırt üstü yatış pozisyonunun bir sonucu olarak geliştiği yaygın olarak kabul edilir. Prematür doğan infantlar ve doğum sonrası uzun süre prone pozisyonda yan yatırılan bebekler dolikosefalik kranium gelişimi yönünden yüksek risklidir. ${ }^{4}$ Çalışmamızda da taburcu edilen preterm bebeklerde kafatası şekil bozukluğu olduğunu gördük.

Preterm infantlar beslenme ve spontan solunumu devam ettirmede zorlanabilmektedir. Ağır kronik akciğer hastalığı nedeni ile mekanik ventilasyon gereksinimi olan preterm infantların uzun süre entübasyon ve OG/NG beslenme ihtiyacı olmaktadır. Orotrakeal ve orogastrik tüplerin, alveolar krest ve damağın medyan bölgesine basınç uyguladığı, palatal büyümeye ve çenenin inişine olumsuz etkide bulunduğu tahmin edilmektedir. Bir çalışmada, OG tüp kullanımının her ek günü için palatal oluk gelişim riskini \% 2 artırdığ1 gösterilmiştir. ${ }^{2}$ Başka bir çalışmada palatal oluklanmanın preterm bebeklerde oral beslenmeye geçişi olumsuz etkilediği bildirilmiştir. ${ }^{1}$ Bizim çalışmamızda da hastalarımızın son muayenesinde bir kısmında palatal oluklanma ve diş pulpasında deformasyon gözledik. Palatal oluklanmanın kalıcı olup olmadığı ise bilinmemekte$\operatorname{dir}^{3}$

Binasal pronglar, preterm bebeklere nCPAP uygulanması için sık kullanılan araçlardır. Bununla birlikte, bunlar kolumella üzerine basınca bağlı kan akım hızını azaltabilir. ${ }^{5,6}$ $\mathrm{Bu}$ durum doku perfüzyonunu bozar, doku hasarı ve iskemiye yol açabilir. Kabuklanma, kızarıklık, kanama, endürasyon gibi önlem alındığında tamamen iyileşebilecek komplikasyonlar oluşabilirken kalıcı sekellere neden olan septal perforasyon ve kolumella nekrozu da gelişebilir. ${ }^{7-14}$ Literatürde nCPAP ilişkili bilateral timpanik mempran rüptürü, su intoksikasyonu, aerikular seroma gibi nadir komplikasyonlar bildirilmiştir. ${ }^{15,16} \mathrm{Bu}$ komplikasyonlar nCPAP cihazları ve nazal prongların tüm tipleri ile olușabilir. ${ }^{7-13}$ Bizim çalışmamızda nCPAP ile ilişkili nazal septumda hasar ve antevert nares gözlenmiştir.

Preterm infantlarda kulağın iç ve dış kartilaj tabakası çok hassastır ve vaskülarizasyonu kötüdür. Bu yüzden trofik komplikasyon riski yüksektir. Uzun süreli aynı pozisyonda bulunmak normalde de az kanlanan bu organın kanlanmasını daha da bozarak kulak aerikulasında nekroz ve enfeksiyona zemin hazırlamaktadır. Çalışmamızda hastaların bir kısmında taburcu olurken hayatın ilk günlerindeki muayeneden farklı olarak tek taraflı kulak aerikulaların anterior deviasyonunu tespit ettik. Bu durumun doğumdan sonraki ilk muayenede olmaması ve tek taraflı olması hastaların uzun süre aynı pozisyonda kalmaları ve ince olan kulak aerikulasının kolay katlanabilmesinden kaynaklanabileceğini düşündürmektedir. Çalışmamızda bir hastada psödomonas sepsisine bağlı kulak helixinde nekroz gelişmiş ve nekrotik alan debride edilerek sonrasında rekonstrüksiyon uygulanmıștı.

İntraventriküler kanama, posthemorajik ventriküler dilatasyon ve hidrosefali preterm infantların yönetimde önemli bir sorundur ve kalıcı morbidite ile ilişkilidir. ${ }^{17}$ Progressif ventriküler dilatasyona bağlı olumsuz sonuçları önlemek 
için seri lomber ponksiyon, EVDS, ventrikülo-peritoneal şant, ventrikül içi araç, beyin omurilik sıvısının transaraknoidal aspirasyonu gibi terapötik yaklaşımlara ihtiyaç duyulabilir. ${ }^{18}$ Gerek başın ağırlığında artışa neden olan hidrosefali gerekse preterm infantın motor hareketlerinin yerçekimi kuvvetinden etkilenmesi hastanın baş pozisyonunu kontrol etme yeteneğini kısıtlar. Bu durum özellikle ventrikül içi araç uygulanan hastalarda operasyon yerinin kanlanmanın bozulmasına ve ciltte nekrotik alan oluşumuna zemin hazırlayabilir. Çalışmamızda da görüldüğü gibi yatak zemininin operasyon yeri ile uzun süre teması ve baş hareketlerinin kısıtlı olması o bölgede nekroza ve sonuçta da lokalize alopesi gelişmesine neden olabilir.

Preterm infantların tedavisi sırasında ilaç ekstravazasyonu sıklıkla görülür. Literatürde kalsiyum ekstravazasyonu so- nucu sellülit, osteomyelit, kompartman sendromu bildirilmiştir. ${ }^{19-25}$ Kanlanmanın iyi olmadığg bölgelerde ve büyük lezyonlarda erken cerrahi müdahale ile kalsiyum kristallerinin çıkartılması veya deri grefti uygulaması gerekebilir. Çalışmamızda ilaç ekstravazasyonunun (amfoterisin b, kalsiyum glukonat) hastalarda kontraktür ve doku nekrozuna neden olduğu gözlenmiştir.

Sonuç olarak preterm bebeklerin yaşam şansları arttıkça deformasyona neden olabilecek enstürmanlarla karşılaşmaları da artmaktadır. Başlangıçta bebeklerinin yaşadığının sevincinde olan ebeveynler bu problemleri sorun etmese de bu infantlar büyüdüğünde onlarda psikolojik sorunlara neden olabileceği unutulmamalı ve deformasyon oluşumunu önleyebilmek için gerekli özen gösterilmelidir.

\begin{tabular}{|c|c|}
\hline Demografik özellik & Tanımlayıcı istatistikler \\
\hline Gestasyonel yaş (hafta) (ortalama \pm SS) & $29.36 \pm 2.37$ \\
\hline Doğum ağırlı̆̆ı (gr) (ortalama \pm SS) & $1248.16 \pm 389.4$ \\
\hline Hastanede kalış süresi (gün) (ortalama $\pm S S$ ) & $70 \pm 13$ \\
\hline nCPAP (1 aydan uzun süre Ncpap ihityac1 / Total Ncpap) & $84 / 600$ \\
\hline Mekanik Ventilatör (1 aydan uzun süre MV ihityacı / Total MV ihtiyacı) & $23 / 200$ \\
\hline Periton diyalizi $(\mathrm{n} / \mathrm{N})$ & $24 / 1002$ \\
\hline Göğüs tüpü (n/N) & $104 / 1002$ \\
\hline PDA ligasyon $(\mathrm{n} / \mathrm{N})$ & $7 / 1002$ \\
\hline OG sonda ile taburcu $(\mathrm{n} / \mathrm{N})$ & $40 / 1002$ \\
\hline \multicolumn{2}{|l|}{ Tedavi gerektiren hidrosefali $(\mathrm{n} / \mathrm{N})$} \\
\hline Ventrikülo-peritoneal şant & $13 / 1002$ \\
\hline EVDS & $7 / 1002$ \\
\hline Tekrarlayıcı lomber ponksiyon & $42 / 1002$ \\
\hline Ventrikül içi araç & $9 / 1002$ \\
\hline $\begin{array}{l}\text { SS: Standart sapma, nCPAP: Nazal Sürekli Pozitif Havayolu Basıncı, } \\
\text { MV: Mekanik ventilatör, PDA: Patent duktus arteriosus, OG: Orogastrik, } \\
\text { EVDS: Eksternal ventriküler drenaj sistem }\end{array}$ & \\
\hline
\end{tabular}




\begin{tabular}{|c|c|c|}
\hline Morbidite & Hasta sayısı n (\%) & Risk faktörü \\
\hline Kafa şekli bozukluk & $144(14.4)$ & sürekli sabit pozisyon \\
\hline Plagiosefali & $112(77.8)$ & - \\
\hline Dolikosefali & $32(22.2)$ & - \\
\hline Kulak deformitesi & $30(3)$ & $\begin{array}{l}\text { sürekli sabit pozisyon, bası } \\
\text { yarası sonrası iyileşme }\end{array}$ \\
\hline Kulak aerikulasının nekrozu & $1(3.3)$ & psödomonas sepsisi \\
\hline $\begin{array}{l}\text { Diğer (kulak aerikulasının öne doğru kıvrılması, } \\
\text { kulakta çentiklenme) }\end{array}$ & $29(96.7)$ & - \\
\hline Dudak ve yumuşak damak hasarı & $13(1.3)$ & $\begin{array}{c}\text { uzun süreli entübasyon, } \mathrm{OG} \\
\text { sonda ile beslenme }\end{array}$ \\
\hline Palatal oluklanma & $13(100)$ & \\
\hline Dudak ve diş pulpasında deformasyon & $2(15.4)$ & \\
\hline Nazal septum hasarı & $83(13.8)$ & nCPAP \\
\hline \multicolumn{3}{|l|}{ Skar } \\
\hline Alın & $2(33.3)$ & nCPAP \\
\hline Abdomen & $24(2.4)$ & periton diyaliz \\
\hline Torax & $104(10.4)$ & torax tüpü, PDA ligasyonu \\
\hline Alopesi, saçlı deri skarı & $2(0.2)$ & $\begin{array}{l}\text { hidrosefali tedavisinde rezer- } \\
\text { vuar yerleştirme }\end{array}$ \\
\hline Kalsiyum ve/veya ilaç ekstravazasyou & $4(0.4)$ & \\
\hline Doku nekrozu & $3(75)$ & $\begin{array}{l}\text { Amfoterisin B ve kalsiyum } \\
\text { tedavisi }\end{array}$ \\
\hline Kontraktür & $1(25)$ & hipokalsemi tedavisi \\
\hline \multicolumn{3}{|c|}{ OG: Orogastrik, PDA: Patent duktus arteriosus, nCPAP: Nazal sürekli pozitif havayolu basıncı } \\
\hline
\end{tabular}


Sakarya Tip Dergisi 2019;9(1):16-21

TARAKÇI ve Ark. Prematüre ve Morfolojik Deformite

\section{Kaynaklar}

1. Enomoto M, Sezaki H, Muranishi R, Sato Y, Kikuchi S, Katayama Y et al. Acquired palatal groove and delayed oral feeding in preterm infants. Pediatr Int 2017; 59:171-175.

2. Cortines AAO, Costa LR. Associated factors and persistence of palatal groove in preterm infants: a cohort study. BMC Pediatr 2016; 16:143.

3. Molteni RA, Bumstread DH. Development and severity of palatal grooves in orally intubated newborns. Am J Dis Child 1986; 140:357-359.

4. Laughlin J, Luerssen TG, Dias MS. Committee on Practice and Ambulatory Medicine, Section on Neurological Surgery: Prevention and management of positional skull deformities in infants. Pediatrics 2011; 128:1236-1241.

5. Imbulana DI, Manley BJ, Dawson JA, Davis PG, Owen LS. Nasal injury in preterm infants receiving non-invasive respiratory support: a systematic review. Arch Dis Child Fetal Neonatal Ed 2018; 103: F29-F35.

6. Günlemez A, Isken T, Gökalp AS, Türker G, Arisoy EA. Effect of silicon gel sheeting in nasal injury associated with nasal CPAP in preterm infants. Indian Pediatr 2010; 47: 265-267.

7. Robertson NJ, McCarthy LS, Hamilton PA, Moss AL. Nasal deformities resulting from flow driver continuous positive airway pressure. Arch Dis Child Fetal Neonatal Ed 1996;75: 209212 .

8. Yong SC, Chen SJ, Boo NY. Incidence of nasal trauma associated with nasal prong versus nasal mask during continuous positive airway pressure treatment in very low birthweight infants: a randomised control study. Arch Dis Child Fetal Neonatal Ed 2005; 90:480-483.

9. Buettiker V, Hug MI, Baenziger O, Meyer C, Frey B. Advantages and disadvantages of different nasal CPAP systems in newborns. Intensive Care Med 2004; 30:926-930.

10. Shanmugananda K, Rawal J. Nasal trauma due to nasal continuous positive airway pressure in newborns. Arch Dis Child Fetal Neonatal Ed 2007; 92: 18.

11. Foster SJ. Nasal deformities arising from flow driver continuous positive airway pressure. Arch Dis Child Fetal Neonatal Ed 1998; 78:157-158.

12. Smedsaas-Lofvenberg A, Faxelius G, Axelsson I, Lagercrantz H. Nasal deformities at a UK hospital. Arch Dis Child Fetal Neonatal Ed 1998; 78:158.

13. Kopelman AE, Holbert D. Use of oxygen cannulas in extremely low birthweight infants is associated with mucosal trauma and bleeding, and possibly with coagulase-negative staphylococcal sepsis. J Perinatol 2003; 23:94-97.
14. Loftus B.C, Ahn J, Haddad Jr J, Neonatal nasal deformities secondary to nasal continuous positive airway pressure, Laryngoscope 1994; 104:1019-1022.

15. Eifinger $F$, Lang-Roth $R$, Woelfl $M$, Kribs A, Roth B. Auricular seroma in a preterm infant as severe complication of nasal continuous positiveairway pressure (nCPAP). Int J Pediatr Otorhinolaryngol 2005; 69: 407-410.

16. Rosenfeld W.N.,Linshaw M., Fox H.A. Water intoxication: a complication of nebulization with nasal CPAP, J. Pediatr 1976; 89:113-114.

17. Whitelaw A, Aquilina K. Management of posthaemorrhagic ventricular dilatation. Arch Dis Child Fetal Neonatal Ed 2012; 97: F229-233.

18. Lam HP, Heilman CB. Ventricular Access device versus ventriculosubgaleal shunt in post hemorrhagic hydrocephalus associated with prematurity. I Matern Fetal Neonatal Med 2009; $22: 1097-1101$

19. Chen TK, Yang CY, Chem SJ.Chen SJ. Calcinosis cutis complicated by compartment syndrome following extravasation of calcium gluconate in neonate: a case report. Pediatr Neonatol 2010; 5:238-241.

20. Moss J, Syrengelas A, Antaya R, Lazova R. Calcinosis cutis: a complication of intravenous administration of calcium gluconate. J Cutan Pathol 2006; 3: 60-62.

21. Millard TP, Harris AJ, MacDonald DM. Calcinosis cutis following intravenous infusion of calcium gluconate. Br J Dermatol 1999; 140:184-186.

22. Mu SC, Lin CH, Sung TC. Calcinosis cutis following extravasation of calcium gluconate in neonates. Acta Paediatr Taiwan 1999; 40:34-35.

23. Chiang MC, Chou YH, Wang CR, Huang CC. Extravasation of calcium gluconate concomitant with osteomyelitis in a neonate. Acta Paediatr Taiwan 2004; 45:35-37.

24. Arora A, Agarwal A, Kumar S, Gupta SK. Iatrogenic calcinosis cutis: a rare differential diagnosis of soft-tissue infection in a neonate-a case report. J Orthop Surg 2005; 13:195-198.

25. Soon SL, Chen S, Warshaw E, Caughman SW. Calcinosis cutis as a complication of parenteral calcium gluconate therapy. J Pediatr 2001; 138:778. 